\title{
Alternative Assessment in History Lessons
}

\section{Akif PAMUK ${ }^{1}$}

\author{
SUMMARY
}

\section{INTRODUCTION}

The basic component which effects the history teaching programs majorly, is the reflection of the well accepted philosophical and teaching - learning approaches to the program. If the accepted approach is behaviorism, an approach based on positivist epistemology, the history teaching programs consist of, in general, aim, content, teaching learning process and evaluation parts. On the other hand, if constructivism is accepted, capability, gains, teaching - learning process and evaluation becomes the parts. This is a crucial component for the application of the teaching program with the parts that show coherence with each other. Among these parts, the "evaluation part" is much more important as it shows the outcomes of the other three parts. It is expected that the well accepted education approach will define the assessment and evaluation period and allow the nature of the program to become a part of this period.

\section{METHOD}

The aim of this research is discuss to how the alternative quantification program, which is partaking in M.E.B.'s constructivist history teaching program, reflects on teacher's assessment and evaluation approach. The results about history teacher's problems and how constructivist assessment and evaluation approach is being used in the class will be examined. Thus in this research case study technique among the qualitative research forms is being used. Case study technique is a favored technique for understanding different subjects of education, especially when we face with questions like "how" and "why" (Ekiz, 2009:46). Also the factors about case study, like space, people, things, processes, etc., could be searched with a totalitarian approach. Apart from that, it could be focused how these factors are effecting the situation and being effected by the situation (Yıldırım ve Şimşek, 2008: 77). For the case study, usage level of history teacher's constructivist quantification approach will be discussed.

\section{Research Participants and Data Collection Tools}

The working group consists of 8 history teachers, 3 female and 5 male, from the Eyup district of Istanbul. Also, while 3 of them has education experience less than 10 years, rest of them has more than 10 years. In the research among the qualitative research forms, group discussion and document search were being used, which are partaking in the information casting tools. In the context of document researching education books, education programs, correspondences and documents can be use as information sources (Yıldırım ve Şimşek, 2008: 188).

Center interview means making an interview with related characters about a specific subject. Center interviews, which are aiming to increase the interaction between people, are more important than teacher's experience exchange, who works in different schools. History teachers can discourse their own ideas beyond answers when they listen each other's answers. Here, our basic aim is gaining high qualified information about person's own ideas related with other person ideas in social contexts (Patton, 2014: 386). Thus we have reached

\footnotetext{
${ }^{1}$ Dr. Marmara University, Atatürk Education Faculty, akifpamuk@marmara.edu.tr
} 
Cumhuriyet International Journal of Education-CIJE

e-ISSN: 2147-1606

Vol 4 (4), 2015, $29-46$

profound information about quantification approach's quality, using and the problems that they have faced while they are using the quantification approach.

\section{Data Collection and Data Analysis}

Exam papers and answers keys being examined which have prepared by history teachers in their own schools, who have participated to our searching and documenting project. Thus we tried to disclose the quantification tools that have been used by history teachers. After that, we made center interviews with history teachers in Eyup Refhan Tümer Highschool. Before the center interview, first of all the aim of the research and process have given and we build consensus about recording the interviews. Center interview took 65 minutes. Then interview have transferred to WORD program, word by word. The information that have been gained by the document examination and center interviews, examined by content analysis. Content analysis is being used for discoursing the attempts about explaining the meanings and reduction of the information which are qualitative (Patton, 204: 453). Thus with content analysis, the information have being discussed with meaningful contexts.

\section{FINDINGS}

Discoveries will be examined under the titles of assessment and evaluation tools, constructivist assessment and evaluation forms, problems and practicality of assessment and evaluation.

\section{Assessment and Evaluation Tools in History Classes}

First of all, in the center interviews, the teachers' knowledge about assessment and evaluation tools is very important for their own point in the practice. For this purpose method of evaluation that being used by teachers in the exam paper have been examined. Different type of questions also presented for showing the current situation. When exam papers and answers keys have been examined, we realized that the teachers have preferred the classical assessment and evaluation tools.

\section{What is Constructivist Assessment and Evaluation?}

Instead of classical assessment and evaluation tools, constructive assessment and evaluation tools predicts the process, not the result. The importance for the constructive assessment and evaluation approach of the process is based on abilities more than information/behavior. The major aim is revealing that if the students gained the abilities like chronological thinking, historical comprehension, historical analysis and interpretation, historical problem analysis, decision, making research according to the historical interpretation. The teachers that participated in the working group, when they were discussing the constructivist assessment approach, they mentioned that this approach should be based on process; also they mentioned the qualities of the tools and objectivity of the process.

\section{Problems}

As the result of analyzing the content records, we decided to separate the problems that the teachers have been faced in the process to four different categories. These categories are, personal problems that caused by a teacher who used the assessment and evolution approach, problems that caused by school, problems that caused by MEB and problems caused by students.

\section{Practicality}

Assessment and evaluation approach in history lessons is giving to students a context that they can explain themselves and build their own historical perspective. It's been 
understood that in a University exam which is based on classical technique tools, it's not possible to use alternative technic tools.

\section{CONCLUSIONS}

According to the researching results, we reached with history teachers programs like objective point giving, preference of classical quantification tools and asking questions in high level ability quantification. Also, they mentioned that they used the assessments for oral notes (note verbal).

The identifications about constructive quantification program by the teachers are; consideration of process, subjectivity, variability for students and teachers, studying without books, modifiable curriculum. In this context teachers have mentioned that, they have a will for using assessment and evaluation approaches. However they could not use these programs because of lack of substructure, sources, space, population, they also mentioned that they could not use these programs. On the other hand some of the teachers stated that directors and MEB and supervision system have negative approach for assessment and evaluation program. Students stated that in the questions, because of directors and inspectors objectivity apprehension to the alternative quantification methods, they could not use them. Also judging by administration and inspectors, being in the situation like expectations of standards, history teachers adherence to the books and accepting the books as the objective information source causes objectification attempts by them. This situation, instead of giving to students their own historical building chance, it presents the program to students as monadic and macro teaching as an objective form because of the program's character. Thus the programs that which are famous among us as constructivist, they serve in behavioral order. Using classical quantification tools by the teachers, as they stated, it measures student's objective historical information, not historical thinking ability that anticipated by history teaching. This situation brings tension in history teaching program between goal, content, process and quantification. While the structure of the program is constructivist, the process involves behavioral. In other words, encouragement of directors about using the objective quantification tools and contents of the countrywide exams, it reveals that quantication does not work properly with quantificative assessment and evaluation program. Also it reveals that they do not use quantification in the group and selfassessment in the teaching process. 